\title{
Esquerdas, política e cultura no Brasil (1950-1970) \\ um balanço historiográfico
}

Marcos Napolitano ${ }^{1}$

Resumo

Este artigo propõe um balanço crítico da trajetória da arte engajada de esquerda no Brasil, entre 1950 e 1970, com base nos debates bibliográficos consolidados e nas revisões historiográficas mais recentes. O foco da análise recai sobre a trajetória da cultura nacionalpopular e sobre as proposições estéticas desenvolvidas por artistas militantes do Partido Comunista Brasileiro (PCB), que passaram a sofrer uma grande crítica no final dos anos 1960 por outras correntes de esquerda. A partir dessa perspectiva central, analiso as lacunas e contradições no âmbito da análise historiográfica provocadas pela excessiva dependência desta em relação à memória produzida pelos sujeitos históricos em disputa.

Palavras-chave

Arte e política, Brasil: história cultural, Nacional-popular: Brasil.

Recebido em 31 de julho de 2013

Aprovado em 14 de março de 2014

NAPOLITANO, Marcos. Esquerdas, política e cultura no Brasil (1950-1970): um balanço historiográfico. Revista do Instituto de Estudos Brasileiros, n. 58, p. 35-50, jun. 2014.

DOI: http://dx.doi.org/10.11606/issn.2316-901X.v0i58p35-50

1 Universidade de São Paulo (USP, São Paulo, SP, Brasil). 


\title{
Politics and Culture in the Brasilian Left a Historiographical Balance
}

\author{
Marcos Napolitano
}

\begin{abstract}
This article offers a critical assessment of the trajectory of committed left art in Brazil between end of the 1950's and end of the 1970's, based on established bibliographic debates and more recent historiographical revisions. The focus is on the trajectory of the national-popular culture and the aesthetic propositions developed by artists linked to the Brazilian Communist Party (PCB), which suffered a major criticism from the late 1960's by other left currents. From this central perspective, we analyze tensions and contradictions within the established historiography on Brazilian left culture, caused by its excessive tribute to the memory produced by historical protagonists involved in cultural struggles in the 1960's and 1970's.
\end{abstract}

Keywords

Art and politics, Brazil: cultural history, National-popular: Brazil. 

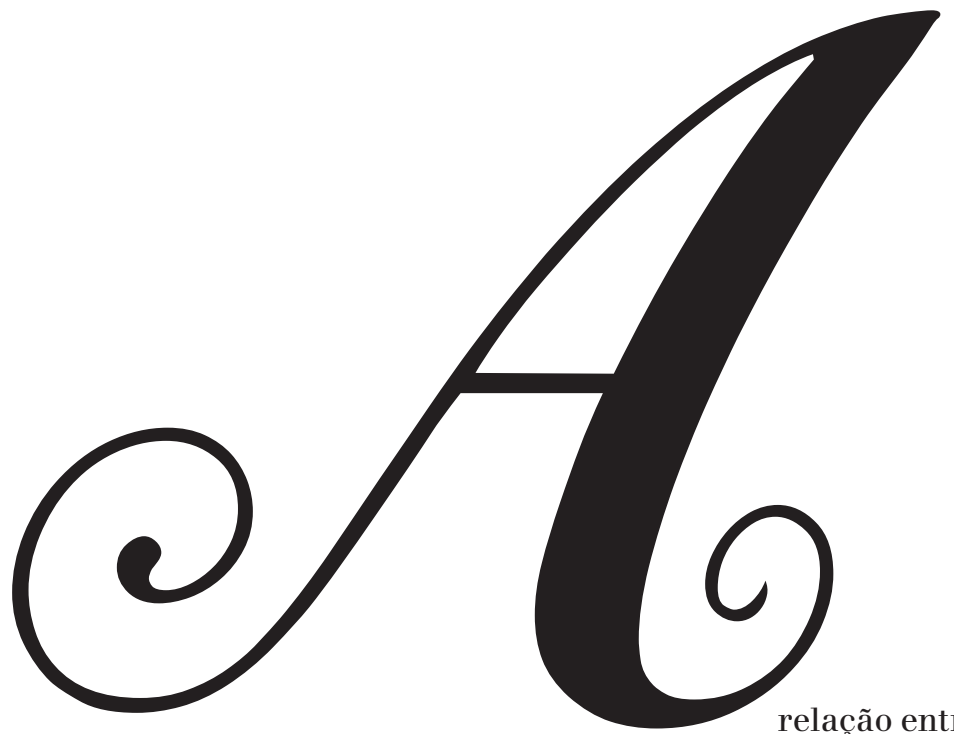

relação entre as esquerdas e a cultura, incluindo-se nesse campo a produção artística, constitui-se em um campo quase inesgotável de questões e debates teóricos e políticos. Com a estruturação dos grandes partidos e organizações ligadas ao movimento operário na Europa, no último quarto do século XIX, antigos problemas e debates, motivados pela Revolução Francesa e pelo uso da cultura em situações revolucionárias, ganharam nova densidade, gerando debates intensos que envolveram grandes líderes políticos e intelectuais militantes como Plekhanov, Lênin, Trotsky, Lukács, Gramsci, Brecht, entre outros. Após a Revolução Russa, os "problemas culturais" ou o "front cultural", para utilizar as expressões caras aos marxistas, configuraram um debate bastante sofisticado, sobretudo entre os anos 1920 e 1930². Após a II Guerra, o chamado "marxismo ocidental", a começar pela Escola de Frankfurt, tomou a questão cultural como um eixo central de suas reflexões sobre as sociedades capitalistas avançadas, caminhando para uma revisão crítica das relações entre cultura e revolução ao longo da segunda metade do século XX. Em certa medida, tanto o capitalismo avançado e sua poderosa indústria cultural, como os efeitos da traumática relação da União Soviética stalinista com o campo artístico-cultural, constituíram-se nos problemas centrais a serem debatidos e criticados, apontando-se para outra relação possível entre engajamento político e ação cultural.

2 LUNN, Eugene. Marxismo y Modernismo: un estudio historico de Lukács, Brecht, Benjamin y Adorno. Mexico: Fondo de Cultura Economica, 1986. Para uma síntese das categorias e conceitos derivados desse debate, bem como sua aplicabilidade na pesquisa histórica, ver NAPOLITANO, Marcos. A relação entre arte e política: uma introdução teórico-metodológica. Temáticas, Revista de Pós-graduação em Sociologia/Unicamp, Campinas, v. 37-38, p. 25-56, 2011. 
Esse breve introito ao tema central não tem a pretensão de, sequer, esboçar o mapa do grande debate sobre a cultura e as artes no campo marxista ou na tradição maior das esquerdas. O que pretendo aqui é sublinhar os problemas centrais que, em certa medida e sob outras circunstâncias históricas, serão vivenciados pela esquerda brasileira, particularmente a esquerda comunista, durante o segundo pós-guerra. Em linhas gerais, os eixos centrais configurados no debate da esquerda marxista europeia também estarão presentes no ambiente cultural brasileiro, muitas vezes sem a densidade teórica que marcava o contexto europeu, mas sempre configurados de maneira dramática e dilemática, reveladora da rica historicidade do período, marcada pela afirmação de uma política de massas voltada para a superação do subdesenvolvimento histórico. Os temas são os seguintes: os limites entre reflexão e crítica intelectual militante; as tensões entre arte e propaganda; o lugar da cultura no conjunto da chamada "superestrutura" da sociedade; o papel da arte para a construção de uma consciência revolucionária e progressista; a relação entre o artista e o intelectual com o Partido (questão esta particularmente complexa no caso dos Partidos Comunistas altamente centralizados e burocratizados).

Reconheço que o amplo leque das esquerdas e o problema do engajamento vão muito além da tradição marxista-leninista e da esfera de influência dos partidos comunistas construídos sob a influência sovié tica $^{3}$. Entretanto, devido aos limites e à natureza deste texto, tentarei analisar a ação cultural das esquerdas a partir de um recorte mais preciso, centrado no protagonismo dos artistas e intelectuais filiados ou atraídos pelo Partido Comunista Brasileiro (PCB) ${ }^{4}$. A meu ver, a exposição e a análise dos eventos ligados à vida cultural pecebista podem articular problemáticas mais amplas para pensar a vida cultural brasileira, tais como o modernismo, o folclorismo ${ }^{5}$, o nacionalismo e o

3 SARTRE, Jean Paul. O que é literatura? 2. ed. São Paulo: Editora Ática, 1993.

4 Para um panorama crítico da produção cultural pecebista ver NAPOLITANO, Marcos; MOTTA, Rodrigo Patto S.; CZAJKA, Rodrigo (orgs.). Comunistas Brasileiros: cultura política e produção cultural. Belo Horizonte: Editora UFMG, 201z. É preciso lembrar que o grau de militância e organicidade do artista com o Partido poderia variar conforme o caso, havendo desde simpatizantes que frequentavam células até filiados que ocupavam cargos na estrutura formal do Partido.

5 O folclorismo, movimento de promoção e estudos do folclore protagonizado por intelectuais, atraiu grande número de importantes intelectuais brasileiros desde o fim do século XIX. A partir dos anos 1930, ganhou peso na própria burocracia cultural do Estado, transformando-se em movimento intelectual nos anos 1940. A chave folclorista começou a entrar em declínio, durante os anos 196o, com a afirmação de uma sociologia da cultura mais afinada com métodos críticos de pesquisa acadêmica e científica. Nesse momento a noção de cultura popular passou a 
frentismo cultural. Esses temas nos fornecem uma pauta fundamental de reflexão sobre o problema da "cultura brasileira", suas formações, faturas, circuitos e impasses.

Desde os anos 1930, ao menos, os comunistas brasileiros desenvolveram forte atuação na área artística e cultural. A dita "literatura regionalista" ou "literatura social" brasileiras contaram com escritores comunistas ou simpatizantes como seus principais representantes. Jorge Amado, Graciliano Ramos, Patrícia Galvão, Carlos Drummond de Andrade, José Lins do Rego, entre outros, filiados ou simpatizantes do Partido, desenvolveram boa parte dos seus escritos tentando articular a representação dos dilemas históricos brasileiros e as mazelas sociais do país, com o imperativo do engajamento cultural estimulado pelos influxos que vinham da União Soviética. Também estava presente o diálogo com o modernismo e seu ativismo artístico e cultural na construção de um novo Brasil, a partir do revigoramento do "povonação" e das próprias elites culturais que deveriam conduzir o Brasil a uma nova etapa histórica. No caso dos comunistas, obviamente, tratava-se idealmente da construção de uma contra-elite capaz de expandir a consciência revolucionária das massas e de conduzir a revolução.

Ao longo dos anos 1930, sob signos ideológicos e políticos cruzados e conflitantes, a esquerda e a direita compartilhavam da missão de delinear uma nova e genuína "brasilidade". Além desse legado, que será fundamental para a compreensão da ação cultural das esquerdas após-1945, a década de 1930 também foi importante para a percepção dos dilemas e dificuldades na "figuração do outro" no campo artístico e cultural $^{7}$. Neste caso, a assimetria de classes ganhava contornos ainda mais dramáticos para o artista de esquerda, agravada pelo abismo educacional que separava intelectuais letrados e trabalhadores que deveriam constituir o seu público idealizado (operariado e campesinato). Esse problema, adensado por outras conjunturas e situações históricas, perpassará a ação cultural das esquerdas também no segundo pós-guerra. Outro elemento importante do engajamento artístico e intelectual dos anos 1930 para a

ser tratada de outra maneira, como parte da reflexão sociológica ou antropológica. Apesar dessa crítica, o material dito folclórico continuou atraindo muitos artistas, inclusive os de esquerda. Ver VILHENA, Rodolfo. Projeto e missão: O movimento folclórico brasileiro (1947-1964). Rio de Janeiro: Funarte; Editora FGV, 1997.

6 RIDENTI, Marcelo. A brasilidade revolucionária. São Paulo: Editora Unesp, 201o. Para uma visão da ação dos intelectuais e artistas comunistas nos anos 1930, ver também PALAMARTCHUK, Ana Paula. Intelectuais, esquerda e cultura no Brasil dos anos 1930. In: ROXO, Marco; SACRAMENTO, Igor (orgs.). Intelectuais partidos: Os comunistas e as mídias no Brasil. Rio de Janeiro: E-Papers/FAPERJ, 2012, p. 43-72.

7 BUENO, Luis. Uma história do Romance de zo. São Paulo: Edusp, 2009. 
compreensão da esquerda do pós-guerra foi a construção de tipos literários que terão longa vida nas artes engajadas brasileiras. Jorge Amado, nesse sentido, criou modelos de personagens que chegarão ao cinema nos anos 1950, como, por exemplo, o malandro solidário ao operário de Rio, 40 graus (de Nelson Pereira dos Santos, 1954). Seus protótipos de vilóes e heróis também chegarão à teledramaturgia, sobretudo pela mão de outro baiano comunista, Dias Gomes ${ }^{8}$. Mas a linhagem de tipos populares que marcarão as canções, o teatro e o cinema engajado dos anos 1950 a 1970 não é tributária apenas dos escritores de esquerda dos anos 1930. A direita nacionalista também consolidou "tipos humanos brasileiros" sob a égide do folclorismo. Órgão do DIP estado-novista, a revista Cultura Política em sua seção de folclore, sob a responsabilidade de Basílio Guimarães, disseminará personagens idealizados que povoarão as canções de protesto, os filmes e as peças engajadas nos anos 1960, tais como o pescador e o vaqueiro. Nesse ponto reside um dos grandes debates historiográficos sobre a cultura de esquerda no Brasil: seria uma mera apropriação progressista do nacionalismo da direita autoritária dos anos 1930 ou, já nessa década, a esquerda seria uma das vertentes de construção da "brasilidade"?

$\mathrm{O}$ fato é que o nacionalismo, em um amálgama que por vezes confunde as heranças simbólicas da direita e da esquerda, marcou o debate cultural e a produção artística ligada de alguma maneira ao PCB. Com a consagração da expressão "nacional-popular" em meados dos anos 1950, um novo projeto parecia se afirmar na política e na cultura, fazendo com que comunistas e trabalhistas convergissem em vários pontos, esboçando um projeto global de mudanças para o Brasil ${ }^{10}$. Esse projeto ganhou corpo no final dos anos 1950 e fez com que, paulatinamente, os temas da reforma e da revolução - debate caro às esquerdas marxistas - ficassem

8 Para uma síntese da trajetória de Dias Gomes, ver SACRAMENTO, Igor. Dias Gomes e a intelectualidade comunista nas modernizações midáticas: rádio e televisão (1944-1979). In: ROXO, Marco; SACRAMENTO, Igor (orgs.). op. cit., p. 32536o. A teledramaturgia comunista também foi analisada, em sentido mais amplo, dentro da linhagem do realismo crítico por CARDENUTO, Reinaldo. A sobrevida da dramaturgia comunista na televisão dos anos 1970. O percurso de um realismo crítico em negociação. In: NAPOLITANO, Marcos; MOTTA, Rodrigo Patto S.; CZAJK A, Rodrigo (orgs.). op. cit. p. 85-106.

9 RIDENTI, Marcelo. op.cit. Ridenti revisa a crítica cultural dos anos 1980, que via na esquerda nacionalista uma extensão do nacionalismo conservador, defendendo a tese de que o nacionalismo de esquerda cumpriu outro papel histórico e tinha uma linhagem histórica e intelectual própria.

10 FERREIRA, Jorge. Jango: uma biografia. Rio de Janeiro: Civilização Brasileira, 2011. 
embaralhados ${ }^{11}$. Esta convergência, alicerçada em um nacionalismo crítico e seletivo (portanto, diferente do nacionalismo integrador da direita), é fundamental para entendermos a chamada "hegemonia cultural da esquerda” entre 1958 e 1968, possibilitando a construção de um frentismo cultural que marcará época na cultura brasileira. Não é por acaso que o interesse em Lukács ganhou novo alento nas publicações do partido, no final dos anos 1950, como teórico do realismo e do frentismo cultural, bases da ação cultural do PCB daquele momento ${ }^{12}$. Esse novo frentismo parecia superar os limites impostos pelo realismo socialista, vivenciado como doutrina partidária no PCB entre 1947 e 1954 ${ }^{13}$. Diga-se que, a rigor, esse foi o único período em que o Partido tentou desenvolver uma efetiva e sistemática política cultural orgânica ${ }^{14}$. O realismo socialista proposto pelo braço direito de Stalin, Andrei Jdanov, no final dos anos 1940, tinha uma série de preceitos estético-ideológicos rigorosamente definidos. Entre eles podemos citar a busca da comunicabilidade da obra, a ênfase em conteúdos temáticos e dramáticos simplistas, a fusão entre cultura popular e formas da "herança cultural burguesa", o culto ao "herói positivo" e modelar que pudesse dar exemplos de ação revolucionária sem maiores hesitações. No Brasil, sua maior expressão se deu na publicação da coleção "Romances do Povo" e no debate sobre a música erudita de caráter nacionalista ${ }^{15}$.

Apesar de certo dirigismo partidário, e das "patrulhas ideológicas" que sempre marcaram o PCB na área cultural, após 1955 não se pode falar, rigorosamente, em uma política cultural ampla, coerente e orgânica por parte da direção partidária pecebista. Por outro lado, muitos artistas e intelectuais tentarão constituir um núcleo duro de ação e direção cultural, como atesta, por exemplo, a ação do chamado "Comitê Cultural da Guanabara" a partir do final dos anos 1950.

A rigor, a produção artística efetiva dos comunistas, mesmo nos tempos duros do realismo socialista, estava além dos estreitos limites do

II SEgATTO, José A. Reforma e Revolução: as vicissitudes políticas do PCB. Rio de Janeiro: Civilização Brasileira, 1990.

12 FREDERICO, Celso. A presença de Lukács na política cultural do PCB e na universidade. In: MORAES, João Quartim (org.). História do Marxismo no Brasil: influxos teóricos. Campinas: Editora Unicamp, 2001, v. 2, p. 183-222.

13 MORAES, Denis. O imaginário vigiado. A imprensa comunista e o realismo socialista no Brasil. Rio de Janeiro: José Olympio, 1994.

14. RUBIM, Antonio Canelas. Partido comunista brasileiro: política e produção cultural. 1987. 4.15 p. Tese (Doutorado em Sociologia) - Faculdade de Filosofia, Letras e Ciências Humanas, Universidade de São Paulo, 1987.

15 EGG, André. O debate no campo do nacionalismo musical no Brasil (anos 1940 e 1950): o compositor Guerra Peixe. 2004, 243 p. Dissertação (Mestrado em História) Setor de Ciências Humanas Letras e Artes, Universidade Federal do Paraná, 2004. 
jdanovismo, a sua versão mais autoritária. Se houve um movimento nas artes plásticas (por exemplo, Clubes de Gravura) e na música erudita constrangido por esta doutrina, no cinema ou na música popular, por outro lado, os artistas comunistas dialogavam com outras influências que julgavam ser mais pertinentes na busca da comunicação com as massas, como o melodrama e as chanchadas, e com o samba. Cinema e música popular estavam menos afeitos ao folclorismo estilizado do realismo socialista e mais próximos das influências do mercado e do gosto das massas urbanas brasileiras. Filmes como Agulha no palheiro (de Alex Viany, 1952) ou Tudo azul (de Moacyr Fenelon, 1951) são exemplos desses diálogos improváveis ${ }^{16}$ e mesmo no primeiro Nelson Pereira dos Santos, esses elementos estarão presentes.

O surgimento do Centro Popular de Cultura da UNE, em 1962 (já esboçado um ano antes no Rio de Janeiro), modificará o quadro de produção cultural e afirmará a "hegemonia cultural" dos comunistas na área cultural. Diga-se que o CPC não era inteiramente formado por jovens militantes comunistas, mas é inegável que a presença de nomes importantes da área cultural do Partido, como Leon Hirszman, Carlos Lyra e Oduvaldo Vianna Filho (posteriormente Ferreira Gullar), deu o tom da entidade. O Teatro de Arena de São Paulo, em parte egresso do Teatro Paulista do Estudante (este, sim, composto por jovens comunistas), também foi outro núcleo importante de afirmação cultural e artística realizada em nome do Partido. Se o CPC, inicialmente, era pautado pela busca de um agitprop eficaz em tempos de mobilização popular, buscando uma linguagem mais direta e imediata com as massas, o Arena em sua primeira fase (antes de Augusto Boal, diga-se) era marcado pela expressão do grande drama popular, base do "desentorpecimento da consciência alienada”, como escrevera Gianfrancesco Guarnieri em 1958.

O famoso "Anteprojeto de Manifesto do CPC", escrito por Carlos Estevam Martins, nunca passou exatamente disto: de um anteprojeto. Tomado como sinônimo da produção cultural da entidade sem maiores mediações, em críticas posteriores ${ }^{17}$, o manifesto foi responsável mais por gerar debates e polêmicas internas do que por alinhar os artistas e intelectuais em torno da utopia da "arte popular revolucionária", definida nos termos do manifesto como propositalmente tosca no plano estético e acessível às massas. Novas abordagens historiográficas vêm revelando o

16 NAPOLITANO, Marcos. Suicidas e Foliões: chanchada, carnavalização e realismo no filme Tudo azul (Moacyr Fenelon, 1951). Estudos Históricos, Rio de Janeiro, CPDOC/FGV, v.26, n. 51, p. 133-153, jan.-jun. 2013.

17 CHAUI, Marilena. Seminários. São Paulo: Editora Brasiliense, 1981. 
grande debate interno que se seguiu ao manifesto, opondo os dramaturgos e cineastas que gravitavam em torno do CPC na busca de dirigismo intelectual e estético ${ }^{18}$. Os primeiros não recusavam o profissionalismo e o drama burguês bem feito como possibilidades de expressão teatral, os segundos não abriam mão do diálogo com as vanguardas cinematográficas em nome da comunicabilidade. Portanto, o manifesto deve ser visto dentro da sua historicidade e de seus limites como documento histórico, e não como expressão inequívoca da arte cepecista. A pluralidade estética no interior do cepecismo e dos seus herdeiros vai além dos termos reducionistas do seu manifesto e também dos próprios discursos dos artistas, em muitos casos, só perceptível na análise das obras. O realismo (mesclado à incorporação da cultura popular) será efetivamente uma das marcas da dramaturgia comunista, cuja linhagem cepecista será continuada pelo Grupo Opinião e frequentemente irá se opor ao teatro da agressão representado pelo Oficina a partir de 1967. A linhagem brechtiana do Arena pós-Boal (c. 1964) completará a tríade de variantes dramatúrgicas daquele momento. A riqueza desta cena está muito além da oposição forma versus conteúdo ou pesquisa estética versus engajamento político. Em todos os três grupos estas polaridades, vividas como dilemas vivos da criação artística, estarão presentes. Esta questão deve reorientar os olhares historiográficos sobre não apenas a cena teatral, mas sobre todas as manifestações culturais engajadas daquele contexto brasileiro.

Nos anos 1960, o teatro, a música popular e o cinema serão linguagens privilegiadas da ação cultural da esquerda comunista. Mais que meros veículos de ideias políticas, as peças, filmes e canções serão espaços de criação e de pesquisa estética, mesmo sob o signo do nacional popular, de certo convencionalismo estético e do realismo (dramatúrgico). Quero com isso reafirmar o risco de reiterarmos os termos do debate estéticoideológico produzido pelos protagonistas críticos da arte engajada da época, que opôs o pretenso conservadorismo estético do nacional-popular (de influência comunista) às vanguardas formalistas e cosmopolitas ${ }^{19}$. Daí é um passo para uma pretensa oposição forma-conteúdo para pensar o debate artístico e cultural dos anos 1960. No Brasil, a dicotomia entre nacional-

18 GARCIA, Miliandre. Do teatro popular à canção engajada: Carlos Lyra e o CPC da UNE. São Paulo: Editora Fundação Perseu Abramo, 2007.

19 Um exemplo da força dos argumentos dos protagonistas que se transformaram em formas valorativas de analisar o debate pode ser visto no livro organizado por Augusto de Campos, O balanço da bossa. O livro foi originalmente publicado em 1968 , como parte da defesa da arte de vanguarda contra o nacionalismo e o folclorismo. O que era uma crítica pontual, válida para certos artistas, transformou-se em base para a desqualificação mecanicista à corrente nacional-popular como um todo, desconsiderando suas variáveis internas. 
popular e vanguardas que se consideravam herdeiras do modernismo antropofágico - como o Concretismo e o Tropicalismo - deve ser vista com muito cuidado, pois os modernismos brasileiros foram também formuladores de projetos nacional-populares para a cultura. Nesse sentido, o famoso conceito gramsciano que compreende a articulação entre o "dialetal-folclórico" e o "cosmopolita-burguês" é limitado para a compreensão do caso brasileiro, até porque o nacional-popular da nossa esquerda não passara por Gramsci, autor que terá sua entrada no Brasil efetivamente a partir de 1968. Sendo assim, problemas herdados do modernismo, em sua dupla expressão nacionalista e vanguardista, estarão presentes em muitos artistas que a memória social situa em campo oposto das artes engajadas, como Edu Lobo, Caetano Veloso, Hélio Oiticica e Ferreira Gullar. Nem o núcleo nacional-popular per si rejeitava a pesquisa estética, nem a vanguarda deixou de pensar (criticamente) a nação-povo. Esta deveria ser a premissa das pesquisas históricas que desejam ir além dos quadros impostos pelos protagonistas.

O golpe militar de 1964 trouxe novas questões para o campo artístico e cultural da esquerda. Visto como um regime anticultural desde os primeiros tempos do novo regime, esboçou-se uma frente cultural que teve como protagonistas importantes vários artistas comunistas, como os membros do Grupo Opinião, os cineastas mais identificados com o Partido (Nelson Pereira, Gustavo Dahl e Leon Hirszman) ou músicos populares significativos, (Sérgio Ricardo e Carlos Lyra). Esse frentismo cultural contou com o apoio de outras correntes ideológicas, como os próprios liberais, incluindo muitos que até apoiaram o golpe, mas se afastaram do regime que se construiu ${ }^{20}$. Já na segunda metade dos anos 1960, o frentismo cultural passou a ser problematizado por criadores engajados sob outros valores e conceitos de revolução ou crítica cultural, como Glauber Rocha, José Celso ou mesmo Caetano Veloso (bem como os tropicalistas). Para esta nova vanguarda, o nacional-popular de esquerda fora tragado pelo mercado e pelo conservadorismo estético que, ao fim e ao cabo, alimentava o conservadorismo político. A "grande família comunista” começava a se

20 O papel de intelectuais liberais, como Alceu Amoroso Lima, na crítica cultural ao regime militar muitas vezes passa despercebido. Uma parcela significativa dos empresários da cultura e da mídia, até por razões mercadológicas, também deram abrigo à arte engajada de esquerda entre os anos 1960 e 1970 , sobretudo no setor televisual, impresso e teatral. NAPOLITANO, Marcos. Coração civil. Arte, resistência e lutas culturais durante o regime militar brasileiro. 2011. 374 p. Tese (Livre Docência em História do Brasil Independente) - Faculdade de Filosofia, Letras e Ciências Humanas, Universidade de São Paulo, 2011. 
dissolver, tanto na política e quanto na cultura ${ }^{21}$. Mas podemos afirmar que o frentismo cultural defendido pelo PCB terá algum vigor até o final dos anos 1970 e que suas implicações, realizações e vicissitudes já começam a ser estudadas pela historiografia ${ }^{22}$.

No debate cultural afirmado ainda nos anos 1970, o nacionalpopular de esquerda, bem como a ação cultural do Partido Comunista que o afiançava, foi visto como expressão sem lastro histórico a partir da nova conjuntura imposta pelo golpe militar, posto que um dos seus pilares centrais - o contato direto entre artistas engajados e organizações populares - fora cortado pelos militares mesmo antes do AI-5. A ruptura do circuito esboçado no período do CPC teria circunscrito a arte de esquerda, bem como os seus debates culturais, a um "circuito fechado" de comunicação entre intelectuais. Quando muito haveria uma comunicação entre intelectuais e sua base social, a classe média, que se encaminhava para a diluição no mercado e sua consequente neutralização política ${ }^{23}$. Outros autores que estabeleceram diretrizes de análise da cultura dos anos 1960 procuram valorizar justamente o papel das vanguardas formalistas, como a Tropicália, como tomadas de consciência crítica e dessacralizadora desse processo histórico ${ }^{24}$. Esta linhagem crítica influenciou a historiografia do período, apagando muitas vezes as tensões e contradições próprias das lutas culturais.

Entretanto, a tese do "circuito fechado" ou da "falsa consciência" da arte de esquerda pós-Golpe, notadamente aquela defendida pelos comunistas do PCB, devem ser revisadas por novas pesquisas históricas e balizas teóricas. Se estas figurações forem tomadas como absolutas, a cena (e o debate) cultural da época pode ser vítima de uma simplificação. Não que os autores citados sejam simplistas em sua pertinente crítica à arte engajada comunista e nacional-popular. Ao contrário, suas análises são instigantes, bem referenciadas e profundas. Mas é importante não reduzir os dilemas e impasses da produção artístico-cultural da esquerda dos anos 1950 e 1960 a um processo linear e monolítico de absorção pelo mercado

21 RIDENTI, Marcelo. Em busca do povo brasileiro. Rio de Janeiro: Editora Record, 2000.

22 HERMETO, Miriam. 'Olha a Gota que falta': um evento no campo artístico-cultural brasileiro. 2010. 440 f., 4, il. Tese (Doutorado em História) - Instituto de Filosofia e Ciências Humanas, Universidade Federal de Minas Gerais, 2010.

23 SCHWARZ, Roberto. Cultura e Política. 1964-1969. In . Cultura e política. Rio de Janeiro: Paz e Terra, 1999.

24. HOLLANDA, H. B. Impressões de viagem. CPC, Vanguarda e desbunde. São Paulo: Editora Brasiliense, 1981; FAVARETTO, Celso. Tropicália: alegoria, alegria. Cotia: Ateliê Editorial, 1995; XAVIER, Ismail. Alegorias do subdesenvolvimento. Cinema Novo, Tropicalismo e Cinema Marginal. São Paulo: Editora Brasiliense, 1992. 
e de sua consequente neutralização enquanto projeto de ação cultural crítica. Se for verdade que a vertente comunista, sobretudo, aderiu ao grande mercado da cultura nos anos 1970, cujo grande paradigma é a ida em massa dos dramaturgos e atores comunistas para a Rede Globo, esse processo não esteve isento de conflitos, dissensos e variáveis internas, inclusive no plano estético. A ocupação desse espaço de atuação deve ser analisada de acordo com o setor específico do mercado, mais ou menos marcado pela presença das grandes corporações, nacionais ou multinacionais, ou pelo grau do processo de criação mais ou menos capitalizado e industrializado. Também deve ser levado em conta que a "ida ao mercado" por parte dos artistas de esquerda, particularmente os comunistas, não significou a imposição de um estilo único de expressão. Por exemplo, os produtos audiovisuais de Dias Gomes e de Vianinha na Rede Globo eram bem diferentes entre si, ainda que se pautassem pela matriz nacional-popular e pelo realismo crítico. O mesmo poderia ser dito sobre os filmes de Leon Hirszman e de Nelson Pereira dos Santos, cineastas marcados pela trajetória em diálogo com as posições do PCB. Desconsiderar esta riqueza de caminhos e opções da arte engajada nos anos 1970, mesmo dentro da matriz nacional-popular, é passar uma borracha na história como experiência plural e indeterminada em nome de um movimento linear pré-determinado pelos males de origem - a "ida ao mercado". ${ }^{25}$

Um exemplo desse processo histórico-cultural complexo é a música popular. A MPB, em grande parte um tipo de canção formulada sob a égide do nacional-popular na era dos Festivais da canção, foi fundamental na formação da moderna indústria fonográfica brasileira, bem como formatou o gosto musical da classe média escolarizada ${ }^{26}$. A afirmação pode soar exagerada e contrária à memória heroica que se formou em torno da sigla, mas basta um exame do papel dos artistas de MPB na formação de um catálogo estável para as gravadoras, possibilitando faturamento no longo prazo, o que as canções e artistas da "faixa comercial" não possibilitavam. Além disso, os LPs de MPB possuíam alto valor agregado, mobilizavam o que havia de melhor em termos de estúdios, músicos e técnicos, permitindo a fidelização de um público de bom poder aquisitivo em torno de artistas referenciais da "resistência cultural", como o próprio Chico Buarque, um excelente vendedor de discos nos anos 1960 e 1970. Esta constatação

25 Para uma visão de correntes engajadas, além do PCB, que recusaram a "ida ao mercado" ou tentaram criar espaços alternativos ao mainstream do consumo cultural no Brasil dos anos 1970, ver NAPOLITANO, Marcos, op. cit, 2011.

26 NAPOLITANO, Marcos. Seguindo a canção: engajamento político e indústria cultural na MPB (1959-1969). São Paulo: Annablume/Fapesp, 2001. 
não diminui a importância da MPB como epicentro de uma educação sentimental e cívica (talvez mais do que propriamente "revolucionária") no seio de uma esfera pública cerceada pelo regime militar. $\mathrm{O}$ teatro também deve ser analisado com mais cuidado pelos historiadores. $\mathrm{O}$ drama realista, tão defendido pelos comunistas nos anos 1970, como antídoto contra a fuga das plateias e a crise do teatro brasileiro, não pode ser reduzido a um conjunto de peças lineares e simplistas ou que teriam caído na armadilha catártica do “drama burguês”. Os clássicos Gota D’Água (de Chico Buarque e Paulo Pontes), Grito Parado no Ar (de Gianfrancesco Guarnieri) e Rasga Coração (de Oduvaldo Vianna Filho), por exemplo, são obras identificadas com esta corrente e atestam a complexidade das questões veiculadas pela arte de esquerda, já no contexto da resistência cultural durante o AI-5. Se esses campos artísticos e suas obras exemplares são permeadas por uma sensibilidade nacional-popular que frequentemente descambava para o populismo e para as idealizações do "povo" como herói da história, essas questões devem ser vistas como parte dos dilemas enfrentados pelos artistas, cuja tentativa de "superação" conheceu vários caminhos dignos de análise cuidadosa que já tem autores referenciais ${ }^{27}$. Sua presença, estruturante no gosto médio chancelado pelo mercado, deve ser analisada sem que o juízo de valor imposto pelos debates de época - "engajados caretas" contra "vanguardistas desbundados" - obscureça as contradições mais profundas ou as eventuais faturas que representaram para a consciência social e para o desgaste político da ditadura.

A partir do final dos anos 1970, o nacional-popular foi duramente criticado pela nova esquerda, frequentemente confundido com o valor estético-ideológico central do PCB das décadas anteriores. Portanto, criticar o nacional-popular significava criticar a velha esquerda, abrindo caminho para novas formulações e propostas partidárias e ideológicas. Nesta revisão crítica, o nacionalismo de direita e de esquerda foram, propositalmente, embaralhados, comparados e criticados como mistificações dos conflitos sociais mais profundos ${ }^{28}$. Ambos seriam dissolventes de uma verdadeira consciência classista e revolucionária, embora os comunistas até pensassem o contrário, o que criou um descompasso entre a "consciência cultural" e a "consciência social" que vitimara não somente as massas, mas também o intelectual que se pensava revolucionário ${ }^{29}$.

27 PATRIOTA, Rosângela. A crítica de um teatro crítico. São Paulo: Editora Perspectiva, 2007; Vianinha- um dramaturgo lançado no coração de seu tempo. São Paulo: Hucitec, 1999; GARCIA, Miliandre. Políticas culturais no regime militar: a gestão de Orlando Miranda no SNT e os paradoxos da hegemonia cultural de esquerda (1974-1979). In: NAPOLITANO, Marcos; CZAJKA, Rodrigo; MOTTA, Rodrigo Patto Sá (orgs.). op. cit., p. 131-150.

28 CHAUI, Marilena. op. cit.

29 MOTA, Carlos G. Ideologia da cultura brasileira. 4. ed. São Paulo: Ática, 1998. 
Esse debate tem um pano de fundo histórico preciso e delimitado. As questões que explodiriam no final dos anos 1970, em meio a uma crise interna das esquerdas, foram motivadas pelo novo protagonismo do movimento operário e pelo projeto daí surgido, o Partido dos Trabalhadores. As disputas com as esquerdas comunistas e trabalhistas, ambas vistas como limitadas pelo nacionalismo policlassista derrotado em 1964, eram o motor da revisão também na área cultural e marcaram a crise tanto do frentismo político, como do frentismo cultural contra a ditadura. Os esforços intelectuais da nova esquerda engrossaram a crítica de algumas correntes contraculturais que no final dos anos 1960 já criticavam o nacional popular, como o Tropicalismo musical e teatral ${ }^{30}$. Ao lado das vanguardas, um novo mote era utilizado para criticar a ação (e a herança) cultural dos comunistas: a "cultura popular". Esta era vista como tendo uma natureza comunitária que não poderia ser diluída no nacionalismo, ainda que em sua vertente progressista, nem tutelada pelos intelectuais partidarizados. Além disso, a cultura popular não deveria ser confundida com a indústria cultural massificada, lugar de ação cultural sistemática dos comunistas desde o final dos anos 1960. Assim, a pretensa "hegemonia cultural da esquerda"31 parecia ter chegado ao seu limite histórico, ao ser questionada pelas novas correntes de esquerda, diluída no mercado e incorporada em parte pela política cultural do regime militar após a emergência da "Política Nacional de Cultura", em 1975².

Na minha perspectiva, a revisão do nacional-popular como eixo da produção cultural engajada, notadamente a comunista, não pode desconsiderar as críticas pertinentes e sagazes tanto das correntes de vanguarda do final dos anos 1960, como as feitas pela nova esquerda dos anos 1980. Portanto, obviamente, não se trata de recuperar a positividade ou as qualidades estéticas esquecidas da produção cultural comunista sob o signo do nacional-popular. Apenas julgo necessário que a pesquisa

30 NAPOLiTANO, Marcos; VILlaCA, Mariana Martins. Tropicalismo: As Relíquias do Brasil em Debate. Revista Brasileira de História, São Paulo, v. 18, n. 35, 1998. DOI: http://dx.doi.org/10.159o/So102-01881998000100003

31 SCHWARZ, Roberto. op. cit.

32 MICELI, Sérgio. Estado e cultura no Brasil. Rio de Janeiro: Difel, 1984. Esclarecemos que esta incorporação foi seletiva. Em primeiro lugar, o ponto de encontro era o nacionalismo, a defesa dos valores culturais tradicionais ameaçados por um processo de modernização cultural e social sem limites. Embora tivessem visão diferenciada da cultura no processo histórico e político, esquerda e direita desconfiavam do "internacional-popular" patrocinado pelo mercado. Por outro lado, a Política Nacional de Cultura reconheceu que o regime carecia de intelectuais e artistas mais orgânicos e passou a estimular e patrocinar obras realizadas pelos artistas de esquerda, sobretudo no cinema e no teatro, desde que evitassem a crítica direta ao regime e aos seus governantes. 
histórica faça jus à complexidade da cena cultural do segundo pós-guerra no Brasil e, particularmente, do período que se seguiu ao golpe militar, no qual as contradições desta corrente saltaram à vista. A historiografia deve valorizar a historicidade e a experiência plural dos protagonistas e das múltiplas significações dos produtos culturais e artísticos gerados durante o período. Para tal, os paradigmas de análise construídos pelos protagonistas, e suas memórias, devem ser tomados como parte do objeto de análise, mas não como evidências inquestionáveis. O fato de não "fazer a revolução", como se dizia à época, não pode ser tomado como medida de análise da cultura engajada de esquerda, sob o risco de fazer entrar pela porta dos fundos o tão criticado determinismo da esfera política, ou econômica, sobre a cultura. Na chave inversa, a autonomia heróica que a crítica cultural das vanguardas e da nova esquerda se revestiu para questionar a corrente nacional-popular também deve ser tomada como problema histórico e não como um dado inquestionável a partir do qual se pensa a história da cultura. Quando o foco da análise recai em uma ou outra perspectiva, sem maiores mediações, simplifica-se a análise de uma época bastante peculiar na história brasileira, na qual as fronteiras entre o cultural e o político foram diluídas e a artes se afirmaram como sintomas de uma experiência social marcada pela voragem da modernização e da crise das "utopias". A cultura e artes engajadas não foram o reflexo desse processo, mas o caleidoscópio pelo qual ele foi, muitas vezes de forma sagaz, vislumbrado e compreendido ${ }^{35}$.

33 Esta trajetória da cultura de esquerda entre os anos 1960 e 1970 teve amplas significações para a história cultural brasileira como um todo, pautando igualmente a forma pela qual o regime militar passou a ser memorizado pela sociedade. Ao perder a batalha cultural junto às classes médias escolarizadas, o regime não conseguiu se legitimar entre os principais formadores de opinião e produtores simbólicos, perdendo a batalha da memória. Esta talvez seja a grande fatura política da arte engajada no Brasil, ainda que permeada por contradições e ambiguidades. Ver ROLLEMBERG, Denise. Esquecimento das memórias. In: MARTINS FILHO, João Roberto (org.). O golpe de 1964 e o regime militar. São Carlos: EDUFSCar, 2006. p. 81-91. 


\section{Sobre o autor}

\section{Marcos Napolitano}

Livre-docente do Departamento de História da Faculdade de Filosofia, Letras e Ciências Humanas da Universidade de São Paulo. E-mail: napoli@usp.br

Trabalho realizado com o apoio do CNPq. 